\title{
TAS-303, a Novel Selective Norepinephrine Reuptake Inhibitor that Increases Urethral Pressure in Rats, Indicating Its Potential as a Therapeutic Agent for Stress Urinary Incontinence ${ }^{\mathbf{S}}$
}

\author{
Hiroya Mizutani, Fukumitsu Sakakibara, Masahito Komuro, and Eiji Sasaki \\ Discovery and Preclinical Research Division, Taiho Pharmaceutical Co., Ltd., Tsukuba, Ibaraki, Japan \\ Received January 28, 2018; accepted May 30, 2018
}

\begin{abstract}
Stress urinary incontinence (SUI) is characterized by involuntary leakage associated with exertion, effort, sneezing, coughing, or lifting. Duloxetine, a serotonin norepinephrine reuptake inhibitor, is approved for the treatment of patients with SUI in some European countries, but not in the United States. There is currently no globally approved pharmacological drug for the treatment of patients with SUI. Therefore, a new pharmacological treatment option is required. TAS-303 [4-piperidinyl 2,2diphenyl-2-(propoxy-1,1,2,2,3,3,3-day 7 )acetate hydrochloride] is a novel small-molecule selective norepinephrine reuptake inhibitor that displays significant norepinephrine transporter (NET) inhibitory activity toward the serotonin or dopamine transporters. In this report, we describe the pharmacological properties of TAS-303 and its effects on urethral function, using preclinical in vitro and in vivo studies. Radioligand-binding
\end{abstract}

studies showed that TAS-303 selectively and potently inhibited $\left.{ }^{3} \mathrm{H}\right]$ norepinephrine binding to the human NET. Oral administration of TAS-303 (3 mg/kg) significantly increased norepinephrine levels in the plasma, whereas it did not significantly affect epinephrine, dopamine, and serotonin levels. TAS-303 $(0.3,1$, and $3 \mathrm{mg} / \mathrm{kg})$ dose-dependently increased basal urethral pressure in normal rats and leak point pressure in vaginal distention rats, exhibiting a maximal effect comparable to duloxetine. In the forced swimming test, TAS-303 $(100 \mathrm{mg} / \mathrm{kg})$ showed no significant effects on immobility time in rats, raising the possibility that this agent would have minimal central nervous system side effects at an effective dose for urethral function. These results demonstrate that TAS- 303 has therapeutic potential for the treatment of patients with SUI.

\section{Introduction}

Urinary incontinence (UI) is defined as an involuntary leakage of urine and may cause adverse effects on social interactions and psychologic health (Sarkar and Ritch, 2000). UI can be classified into the following three groups: urge UI, stress UI (SUI), and mixed UI. Urge UI is characterized by a sudden desire to void with involuntary voiding and leakage of significant amounts of urine, and is frequently caused by an overactive bladder (OAB). Several pharmacologic treatment options, such as muscarinic $\mathrm{M}_{3}$ receptor antagonists and $\beta_{3}$-adrenoreceptor agonists, are available for OAB. These are recognized to be effective in the improvement of OAB symptoms and to have a good safety profile (Maman et al., 2014). SUI is characterized by involuntary leakage on effort or exertion, or on sneezing or coughing (Abrams et al., 2002). SUI commonly occurs in adults, particularly woman. It has been reported that the prevalence of SUI is $21.5 \%-38.2 \%$ in woman older than 20 years and $52.5 \%$ for those older than

https://doi.org/10.1124/jpet.118.248039.

S This article has supplemental material available at jpet.aspetjournals.org.
50 years (Hannestad et al., 2000; Minassian et al., 2008; Coyne et al., 2012). Previously, some SUI studies have attempted to assess the impact of incontinence on quality of life. In these studies, it was demonstrated that woman suffering from severe SUI hesitated to go outdoors (Grimby et al., 1993; Swithinbank and Abrams, 1999). Although SUI is not considered a life-threatening disease, its impact on patients' quality of life is often devastating and results in social isolation for many. The main cause of SUI is thought to be the damage of muscles and nerves near the urethral sphincter during pregnancy and delivery, leading to the impairment of urethral resistance. In this context, the basic concept of SUI treatment is to increase urethral resistance. Current treatment options for SUI are as follows: surgical therapy, physical therapy, and pharmacological therapy. Surgical therapy is usually conducted for patients with moderate to severe SUI. A review of the literature demonstrated that in women 65 years or younger who underwent mid-urethral sling procedures, SUI cure rates ranged from $73 \%$ to $95 \%$ (Gerten et al., 2008). However, surgical intervention is invasive and has been associated with vaginal erosion, infection, and de novo urge symptoms (Gerten et al., 2008). In physical therapy,

ABBREVIATIONS: DAT, dopamine transporter; DBP, diastolic blood pressure; EUS, external urethral sphincter; HR, heart rate; 5-HT, 5-hydroxytryptamine; $K_{\mathrm{i}}$, inhibition constant; LPP, leak point pressure; MBP, mean blood pressure; NE, norepinephrine; NET, norepinephrine transporter; NRI, norepinephrine reuptake inhibitor; OAB, overactive bladder; SBP, systolic blood pressure; SERT, serotonin transporter; SNRI, serotonin norepinephrine reuptake inhibitor; SUI, stress urinary incontinence; TAS-303, 4-piperidinyl 2,2-diphenyl-2-(propoxy-1,1,2,2,3,3,3day $_{7}$ )acetate hydrochloride; TCA, tricyclic antidepressant; UI, urinary incontinence; VD, vaginal distension. 
postpartum pelvic floor muscle training can be effective for patients with mild to moderate SUI (Mørkved and Bø, 2000). However, in one study (Lagro-Janssen and van Weel, 1998), the majority of women $(61 \%)$ prescribed pelvic floor muscle training for SUI were noncompliant, possibly discouraged by the slow response with the training, and thus failed to dedicate the 15-20 weeks recommended to assess their response.

In pharmacological therapy, duloxetine, a serotonin (5hydroxytryptamine: 5-HT) and norepinephrine (NE) reuptake inhibitor (SNRI) has demonstrated clinical efficacy for patients with SUI (Norton et al., 2002; Dmochowski et al., 2003). Duloxetine is reported to act in both the central nervous system (CNS) and the peripheral nervous system (PNS) (Thor, 2003; Miyazato et al., 2008). In the CNS, it was shown that duloxetine enhanced noradrenergic and serotonergic excitatory control of external urethral sphincter (EUS) spinal motoneurons and evoked contractions of the EUS. In the PNS, duloxetine increased NE levels at sympathetic postganglionic nerve terminals, leading to the activation of peripheral adrenergic $\alpha_{1}$ receptors in urethral smooth muscles. These actions are therefore considered to be the underlying mechanism responsible for its efficacy in women with SUI. However, duloxetine is labeled with a "black box warning" about the increased risk of suicide (Friedman and Leon, 2007). It has been reported that the serotonin system is associated with the onset of the above-mentioned side effect (Oelke et al., 2006; Mann, 2013). In other words, the inhibition of serotonin transporter (SERT) by duloxetine may be involved in the increased risk of suicide. Consequently, duloxetine is not approved for the treatment of SUI in the United States. Because there is no globally approved drug for the treatment of patients with SUI, a new pharmacological treatment option is required. For these reasons, a selective NE reuptake inhibitor (NRI) is a potential therapeutic drug for patients with SUI that lack the side effects associated with SERT inhibition. We created the novel selective NRI TAS-303 hydrochlo-

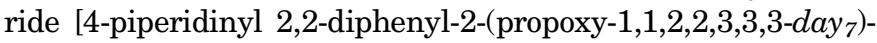
acetate hydrochloride]. In this study, we report that TAS-303 selectively inhibited NE transporter (NET) over SERT or dopamine transporter (DAT) and also inhibited the uptake of $\left[{ }^{3} \mathrm{H}\right]$ norepinephrine in vitro. We also demonstrate that TAS-303 exhibited a dose-dependent increase in basal urethral pressure in normal rats, and in leak point pressure (LPP) in vaginal distention (VD) rats in vivo.

\section{Materials and Methods}

Ethics Statement. All animal experiments were executed according to the Guide for the Care and Use of Laboratory Animals as adopted and promulgated by the US National Institutes of Health and approved by the local Committee of Animal Use and Care of Taiho Pharmaceutical Co. Ltd. (Tsukuba, Japan). Female Sprague-Dawley rats at 10-13 weeks of age (Charles River Laboratories Japan, Inc., Kanagawa, Japan) were used for this study and housed in a controlled environment $\left(24 \pm 1^{\circ} \mathrm{C}, 12\right.$-hour light/dark cycle) with free access to food and water.

Chemicals. TAS-303 hydrochloride was synthesized by Taiho Pharmaceutical Co. Ltd. The TAS-303 synthesis method was previously described (Publication No. WO 2013/115077, published in 2013). The chemical structure of TAS-303 is shown in Fig. 1. Duloxetine hydrochloride was obtained from Bepharm Ltd. (Shanghai, People's Republic of China). $L$-(-)-Norepinephrine (+)-bitartrate salt monohydrate was purchased from Sigma-Aldrich Japan K.K.

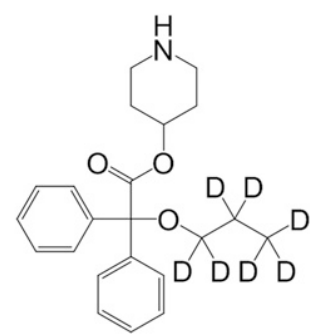

Fig. 1. The chemical structure of TAS-303.

(Tokyo, Japan). Imipramine hydrochloride was obtained from SigmaAldrich.

Transporter Binding. Dilutions of each test compound were made for concentrations ranging from 3 to $3000 \mathrm{nM}$ for TAS-303, and 0.3 to $300 \mathrm{nM}$ for duloxetine. Each assay was performed according to the protocols of Eurofins Pharma Discovery Services Taiwan Ltd. (Taipei, Taiwan). Briefly, Madin-Darby canine kidney cells expressing human NET were used for binding assays in assay buffer (50 mM Tris-HCl, $\mathrm{pH}$ 7.4, $100 \mathrm{mM} \mathrm{NaCl}, 1 \mu \mathrm{M}$ leupeptin, $10 \mu \mathrm{M}$ phenylmethane sulfonyl fluoride). A 40-mg aliquot of membranes was incubated with $0.2 \mathrm{nM}$ $\left[{ }^{125} \mathrm{I}\right] \mathrm{RTI}-55$ (NEX-272; PerkinElmer Inc., MA, USA) for 3 hours at $4{ }^{\circ} \mathrm{C}$. Nonspecific binding was estimated in the presence of the tricyclic antidepressant (TCA) desipramine at $10 \mu \mathrm{M}$. Membranes were filtered and washed three times, and the filters were then counted to determine the specific binding of $\left[{ }^{125} \mathrm{I}\right] \mathrm{RTI}-55$. For binding to SERT, human embryonic kidney 293 cell membranes stably transfected with a plasmid encoding the human SERT were prepared in assay buffer using standard techniques. A 9-mg aliquot of membranes was incubated with $0.4 \mathrm{nM}\left[{ }^{3} \mathrm{H}\right]$ paroxetine for 60 minutes at $25^{\circ} \mathrm{C}$. Nonspecific binding was estimated in the presence of the TCA imipramine at $10 \mu \mathrm{M}$. Membranes were filtered and washed three times, and the filters were counted to determine $\left[{ }^{3} \mathrm{H}\right]$ paroxetine-specific binding. DAT binding assays were conducted using Chinese hamster ovary-S cells expressing human DAT in assay buffer. A 40-mg aliquot of membranes was incubated with $0.15 \mathrm{nM}\left[{ }^{125} \mathrm{I}\right] \mathrm{RTI}-55$ for 3 hours at $4^{\circ} \mathrm{C}$. Nonspecific binding was estimated in the presence of the dopamine reuptake inhibitor nomifensine at $10 \mu \mathrm{M}$. Membranes were filtered and washed three times, and the filters were then counted to determine $\left[{ }^{125} \mathrm{I}\right] \mathrm{RTI}-55$-specific binding. Competition studies were carried out to determine the potencies of unlabeled compounds to displace $\left[{ }^{125} \mathrm{I}\right] \mathrm{RTI}-55,\left[{ }^{3} \mathrm{H}\right]$ paroxetine, or $\left[{ }^{125} \mathrm{I}\right] \mathrm{RTI}-55$ for NET, SERT, or DAT binding to membranes, respectively. All assays were performed in triplicate.

Monoamine Uptake. Each assay was performed according to the protocols of Eurofins Pharma Discovery Services Taiwan Ltd. Briefly, NE uptake was assessed in Madin-Darby Canine Kidney cells expressing human recombinant NET that were plated overnight. Test compounds (TAS-303, 3-3000 nM; duloxetine, 0.3-300 nM) were preincubated with cells $\left(2 \times 10^{5}\right.$ cells $\left./ \mathrm{ml}\right)$ in assay buffer $(5 \mathrm{mM}$ Tris$\mathrm{HCl}, 7.5 \mathrm{mM}$ HEPES, $120 \mathrm{mM} \mathrm{NaCl}, 5.4 \mathrm{mM} \mathrm{KCl}, 1.2 \mathrm{mM} \mathrm{CaCl}_{2}$, $1.2 \mathrm{mM} \mathrm{MgSO}_{4}, 5 \mathrm{mM}$ D-glucose, $1 \mathrm{mM}$ ascorbic acid, $\mathrm{pH}$ 7.1) for 20 minutes at $25^{\circ} \mathrm{C} ; 25 \mathrm{nM}\left[{ }^{3} \mathrm{H}\right]$ norepinephrine was then added and incubated for an additional 15 minutes. After the assay buffer was removed, the cells were washed in assay buffer to remove free $\left[{ }^{3} \mathrm{H}\right]$ norepinephrine. A lysate was obtained from the solubilized cells and counted to determine $\left[{ }^{3} \mathrm{H}\right]$ norepinephrine uptake. Reduction of $\left[{ }^{3} \mathrm{H}\right]$ norepinephrine uptake by $\geq 50 \%$, relative to $10 \mu \mathrm{M}$ desipramine, indicated significant inhibitory activity. Serotonin uptake was assessed in human embryonic kidney 293 cells expressing human recombinant SERT that were plated overnight. Test compounds were preincubated with cells $\left(1 \times 10^{5}\right.$ cells $\left./ \mathrm{ml}\right)$ in assay buffer for 20 minutes at $25^{\circ} \mathrm{C} ; 65 \mathrm{nM}\left[{ }^{3} \mathrm{H}\right]$ serotonin was then added and incubated for an additional 15 minutes. Intracellular $\left[{ }^{3} \mathrm{H}\right]$ serotonin is trapped on the filters. The filters were then rinsed with assay buffer and counted to determine $\left[{ }^{3} \mathrm{H}\right]$ serotonin uptake. Reduction of $\left[{ }^{3} \mathrm{H}\right]$ serotonin uptake by $\geq 50 \%$, relative to $1 \mu \mathrm{M}$ fluoxetine, indicated significant inhibitory 
activity. Dopamine uptake was assessed in Chinese hamster ovary-S/human DAT clone 28 cells expressing human recombinant DAT that were plated overnight. Test compounds were preincubated with cells $\left(4 \times 10^{4}\right.$ cells $\left./ \mathrm{ml}\right)$ in assay buffer for 20 minutes at $25^{\circ} \mathrm{C}$; $50 \mathrm{nM}\left[{ }^{3} \mathrm{H}\right]$ dopamine was then added and incubated for an additional 10 minutes. After the assay buffer was removed, the cells were washed in assay buffer to remove free $\left[{ }^{3} \mathrm{H}\right]$ dopamine. A lysate was obtained from the solubilized cells and counted to determine $\left[{ }^{3} \mathrm{H}\right]$ dopamine uptake. Reduction of $\left[{ }^{3} \mathrm{H}\right]$ dopamine uptake by $\geq 50 \%$, relative to $10 \mu \mathrm{M}$ nomifensine, indicated significant inhibitory activity. If significant inhibition of uptake was observed, the possibility of compound-induced cytotoxicity was evaluated by applying the same concentrations of compounds described above to a separate group of untreated cells.

Measurement of Isolated Urethral Contractions. Female Sprague-Dawley rats 11-13 weeks of age were euthanized by decapitation, and the urethra was isolated. The proximal urethra was cut open and then cut in the traverse direction. Specimens $1.5 \mathrm{~mm}$ in width and $2 \mathrm{~mm}$ in length were prepared. The prepared specimens were transferred to a $37^{\circ} \mathrm{C}$ organ bath $(10 \mathrm{ml})$ filled with KrebsHenseleit solution ( $118 \mathrm{mM} \mathrm{NaCl}, 4.7 \mathrm{mM} \mathrm{KCl}, 2.5 \mathrm{mM} \mathrm{CaCl}_{2}, 1.2 \mathrm{mM}$ $\mathrm{KH}_{2} \mathrm{PO}_{4}, 25 \mathrm{mM} \mathrm{NaHCO}_{3}, 1.2 \mathrm{mM} \mathrm{MgSO}_{4}, 10 \mathrm{mM}$ glucose) saturated with $95 \% \mathrm{O}_{2}-5 \% \mathrm{CO}_{2}$ gas. One end of the specimen was connected to an FD pickup transducer (TB-612T; Nihon Kohden Co., Ltd., Tokyo, Japan) and the other end was fixed to the organ bath. Urethral tension was recorded and analyzed using a PowerLab 16/30 data acquisition system (ADInstruments Pty Ltd, Sydney, NSW, Australia) via an FD pickup transducer and strain pressure amplifier (AP-601G; Nihon Kohden Co., Ltd.). NE-induced urethral contractions were assessed in reference to the previously described method (Pérez-Martínez et al., 2011). A resting tension of $1.0 \mathrm{~g}$ was applied to the isolated urethras, and the specimens were equilibrated for approximately 40 minutes. Ultrapure water $(100 \mu \mathrm{l})$ was added to the organ bath. Ten minutes later, $100 \mu \mathrm{l}$ of a $100 \mathrm{mM} \mathrm{NE}$ solution was added to the vessel and NE-induced urethral contractions were measured. Urethral specimens were washed with Krebs-Henseleit solution, and recovery of tension to the original equilibration level was confirmed 40 minutes after the previous measurement of NE-induced contractions. Then, $100 \mu \mathrm{l}$ of ultrapure water was added to the organ bath. The final concentrations of NE in the organ bath were $1 \mathrm{nM}$ to $1 \mathrm{mM}$. This procedure was repeated until the urethral specimen stabilized, and the data obtained after stabilization were used as the control data. After measurement of the control data, the urethral specimen was washed with Krebs-Henseleit solution. Recovery of resting tension to the original equilibration level was confirmed 50 minutes after previous measurement of NE-induced contractions. A series of solutions (five concentrations) of each test substance was assessed from low concentration to high concentration using the same specimen. The NE ( $1 \mathrm{mM})$-induced maximum contraction when examined with vehicle alone (ultrapure water) prior to the evaluation of test substances because control data were designated as $100 \%$ contraction, and the urethral contractions for each test solution were expressed as relative values $(\%)$. The $\mathrm{EC}_{50}$ value for $\mathrm{NE}$ was obtained from a sigmoidal curve under variable maximum effect conditions.

Determination of TAS-303 Levels in Rat Plasma. A single dose of TAS-303 (1, 3, or $10 \mathrm{mg} / \mathrm{kg})$ was administered by gavage. Blood samples were collected from the jugular vein into heparinized tubes at $0,0.5,1,2,4,8,12$, and 24 hours after administration. These samples were centrifuged at $4^{\circ} \mathrm{C}$, and the supernatants were collected as plasma. Plasma concentrations of TAS-303 were determined using a high-performance liquid chromatographic method combined with tandem mass spectrometry.

Measurement of Monoamine Levels in Plasma. Female Sprague-Dawley rats (10 weeks of age) were divided into a control group $(N=10)$ and a TAS-303 group $(N=9)$. Rats were treated once daily with distilled water or TAS-303 $(3 \mathrm{mg} / \mathrm{kg})$ orally. Rats were anesthetized by intraperitoneal injection of $1.2 \mathrm{~g} / \mathrm{kg}$ urethane 30 minutes after the final administration. Blood samples were collected from the inferior vena cava into tubes containing EDTA as the anticoagulant. A portion of the blood was kept at $-70^{\circ} \mathrm{C}$ for serotonin analysis. The remaining blood was centrifuged at $4^{\circ} \mathrm{C}$, and the supernatant was collected as plasma. The plasma samples were stored in a freezer at $-70^{\circ} \mathrm{C}$ for the analysis of epinephrine, norepinephrine, and dopamine. Monoamine levels were measured by BML Inc. (Tokyo, Japan).

Measurement of Urethral Pressure. Female Sprague-Dawley rats at 11 weeks of age were anesthetized by intraperitoneal injection of $1.2 \mathrm{~g} / \mathrm{kg}$ urethane. After confirming the loss of extremity reflex, an abdominal median incision was performed. Both ureters were ligated with a 4-0 silk ligature, and the ureter was cut at the ligated position near to the kidney. Then, the urethra was ligated tightly with a 4-0 silk ligature. The dome of the bladder was cut open and a catheter (PE-50; Nippon Becton, Dickinson and Company, Ltd., Tokyo, Japan) was placed within, and the opening of the bladder was then sutured with a purse string suture. A three-way stopcock was attached to the other end of the catheter, and the stream was divided into two paths. One was connected to a pressure transducer (DX-360; Nihon Kohden Co., Ltd.), and the other was connected to a syringe filed with physiologic saline and connected to a continuous infusion device (KDS200; KD Scientific Inc., Holliston, MA). An additional catheter was inserted into the urethra from the external urethral orifice. A three-way stopcock was attached to the outer end of this catheter, and the stream was divided into two paths. One was connected to a pressure transducer, and the other was connected to a syringe, as described above. After catheterization, physiologic saline was infused into the bladder at a rate of $10 \mathrm{ml} / \mathrm{h}$ via a microsyringe pump connected to the bladder on a heating board (PS-53; Sakura Finetek Japan Co., Tokyo, Japan). The infusion was stopped when rhythmic contractions of the bladder were confirmed. Physiologic saline was then infused into the urethra at a rate of $3 \mathrm{ml} / \mathrm{h}$, and the inner pressure of the bladder and urethral pressure were measured with a pressure amplifier (AP-641G; Nihon Kohden Co., Ltd.) connected to a pressure transducer, and recorded using the PowerLab 16/30 data acquisition system. TAS-303 at $0.3,1$, or $3 \mathrm{mg} / \mathrm{kg}$ or vehicle (ultrapure water) was administered by gavage to rats 30 minutes prior to urethane anesthesia. For evaluation of duloxetine $(1 \mathrm{mg} / \mathrm{kg})$, rats were subjected to the operation described above and treated intravenously after equilibration of intravesical pressure and intraurethral pressure. Urethral pressure was analyzed by its waveform using Chart version 5.2.2 (ADInstruments Pty Ltd.). The primary evaluation point was set at the urethral baseline pressure, and the effects of duloxetine were assessed relative to the baseline values. After oral treatment, individual urethral baseline pressure was calculated as an average pressure during a period of 30 minutes from 1 hour after administration. For intravenous administration, individual urethral baseline pressure was calculated as an average pressure during the 30-minute period after administration.

Measurement of LPP. Female Sprague-Dawley rats 11 weeks of age were anesthetized by intraperitoneal injection of $50 \mathrm{mg} / \mathrm{kg}$ pentobarbital. After confirming the loss of body reflex, a balloon catheter (JU-LB1005; Terumo Corporation, Tokyo, Japan) was inserted into the vagina. A 4-ml aliquot of physiologic saline was injected into the balloon to expand the catheter. The rats were then placed on a heating board warmed to $37^{\circ} \mathrm{C}$ for 3 hours to maintain VD. Next, the distention was stopped, and the rats were returned to normal housing conditions with free access to food and water. LPP was assessed 4 days after VD model preparation. Rats were anesthetized by intraperitoneal injection of $1.0-1.2 \mathrm{~g} / \mathrm{kg}$ urethane. Rats were placed in a prone position, and the spinal cord was completely severed between thoracic vertebrae 9 and 10 . The rats were then inverted to a supine position, and an abdominal median incision was performed. A vinyl-tube (SV45; Natsume Seisakusho Co., Ltd., Tokyo, Japan) was then inserted and indwelled in the bladder from the dome of bladder. A three-way stopcock was attached to the other end of the catheter; one path was connected to a syringe filed with physiologic saline, and the other was connected to a pressure transducer. Next, the bladder was emptied and 200-350 $\mu \mathrm{l}$ of physiologic saline was injected into the 
bladder. After the instillation of saline, a gentle slow manual pressure increase was applied to the abdomen of the rat by a trained investigator until urethral leakage occurred, stimulating a mild Credé's maneuver, as previously described (Woo et al., 2009). Intravesical pressure at the occurrence time of urine leakage was designated as LPP. Intravesical pressure was measured by a pressure amplifier connected to a pressure transducer, and recorded and analyzed using PowerLab 16/30 data acquisition system. TAS-303 at $0.3,1$, or $3 \mathrm{mg} / \mathrm{kg}$ or vehicle (ultrapure water) was orally administered to the rats 30 minutes prior to urethane anesthesia, and the animals were subjected to surgery for LPP measurement as described above. LPP was measured 1 hour after dosing. For intravenous administration, pre-LPP values were determined prior to the administration of vehicle (physiologic saline) or $1 \mathrm{mg} / \mathrm{kg}$ duloxetine, and LPP was measured again 5 minutes after intravenous administration. The measurement of LPP was conducted in a blinded manner.

Forced Swimming Test. The forced swimming test (FST) was conducted according to the previously described method (Porsolt et al., 1978). A cylindrical acrylic tank $(20 \mathrm{~cm}$ in diameter and $50 \mathrm{~cm}$ in height) was filled with water (at room temperature) to a depth of $25 \mathrm{~cm}$. For acclimatization to the test system, 11-week-old female Sprague-Dawley rats were subjected to a forced swimming trial for 15 minutes 1 day prior to the administration of test substances. The immobility time of rats in the water during the 15-minute acclimatization trial was measured. Any rat showing an immobility time of less than 180 seconds during the 15-minute trial, indicating a lack of apparent depressive condition, was excluded from the study. Based on the immobility time in the trial, rats were categorized as follows. "Swimming" was designated as "the state when rats were moving both fore- and rear-extremities," and "the time of not swimming" was designated as "immobility time." The day after the swimming acclimatization trial, vehicle, TAS-303 (10, 30, $100 \mathrm{mg} / \mathrm{kg})$, or imipramine $(60 \mathrm{mg} / \mathrm{kg})$ was orally administered to rats. One hour after dosing, individual rats were placed in the tank and the FST was conducted for 5 minutes. Immobility time was measured as described above. Evaluation of the results was conducted in a blinded manner.

Statistical Analysis. Results are reported as the mean \pm S.E.M. Statistical analysis was carried out using a Student's $t$ test or Williams' test. A $P$ value $<0.05$ was considered to show statistical significance. All data analyses were performed using SAS version 9.2 and EXSUS version 8.0.0 (CAC Exicare Corporation, Tokyo, Japan).

\section{Results}

Affinity to Monoamine Transporters and Inhibition of Monoamine Uptake by TAS-303. The inhibitory potential of TAS-303 and duloxetine on ligand binding to monoamine transporters was assessed using human NET-, human SERT-, and human DAT-expressing cells (Table 1). TAS-303 selectively inhibited binding of the NE transporter ligand to membranes from cells transfected with human NET relative to the SERTs and DATs. Duloxetine selectively inhibited binding of NE and SERTs relative to the DAT. In functional cell-based assays, the inhibitory effects of TAS-303 and duloxetine on the uptake of NE, serotonin, and dopamine were also evaluated (Fig. 2; Table 2). TAS-303 selectively inhibited the cellular uptake of $\left[{ }^{3} \mathrm{H}\right]$ norepinephrine relative to $\left[{ }^{3} \mathrm{H}\right]$ serotonin and $\left[{ }^{3} \mathrm{H}\right]$ dopamine. Duloxetine selectively inhibited the uptake of $\left[{ }^{3} \mathrm{H}\right]$ norepinephrine and $\left[{ }^{3} \mathrm{H}\right]$ serotonin relative to $\left[{ }^{3} \mathrm{H}\right]$ dopamine.

Effect of TAS-303 on Norepinephrine-Induced Contractions of Rat Isolated Urethra. The effect of TAS-303 on NE-induced contractions of isolated urethral strips was assessed to confirm the efficacy of TAS-303. The reproducibility of consecutive NE-induced contraction-response curves on the same tissue was evaluated in the presence of the vehicle for TAS-303 and duloxetine (ultrapure water). The $\mathrm{EC}_{50}$ values for the concentration-response curves for vehicle are shown in Table 3. Five consecutive vehicle treatments produced no significant change in $\mathrm{EC}_{50}$ values through six trials (Fig. 3; Table 3). Duloxetine shifted the concentration-response curve to the left. Significant differences were observed at concentrations of $10 \mathrm{nM}$ or greater $(P<0.05$ for $10 \mathrm{nM}, P<0.01$ for more than $30 \mathrm{nM}$ ). TAS-303 also shifted the concentration-response curve to the left. A significant difference was observed at a concentration of $100 \mathrm{nM}$ or greater $(P<0.01)$.

Pharmacokinetic Profile of TAS-303 in Rats. The pharmacokinetics of TAS-303 was assessed in female SpragueDawley rats after oral administration (Table 4). TAS-303 (1, 3, or $10 \mathrm{mg} / \mathrm{kg}$ ) was absorbed with a time to peak concentration of $0.75 \pm 0.29,0.75 \pm 0.29$, or $1.25 \pm 0.59$ hours, respectively, in rats. The mean $C_{\max }$ of TAS-303 increased in a dose-dependent manner in rats from $11.7 \pm 5.0,49.1 \pm 13.9$, or $453.0 \pm 28.8 \mathrm{nM}$ for doses of 1,3 , or $10 \mathrm{mg} / \mathrm{kg}$, respectively.

Plasma Monoamine Concentration. To determine the functional effects of TAS-303, rats were administered TAS303 and its ability to increase plasma monoamines was evaluated (Fig. 4). Plasma norepinephrine levels were significantly higher in the TAS-303 group than in the vehicle group. In contrast, there were no differences in plasma epinephrine, dopamine, or serotonin levels between the two groups.

Effect of TAS-303 on Urethral Pressure in Rats. A previous study showed that intravenous injection of duloxetine $(1 \mathrm{mg} / \mathrm{kg})$ significantly increased the basal urethral pressure in rats (Kamo and Hashimoto, 2007). To assess the pharmacological potential of TAS-303 for regulating urethral resistance in vivo, the basal urethral pressure of rats was measured after oral administration (Fig. 5). Intravenous administration of physiologic saline induced no apparent changes in urethral baseline pressure (data not shown). Intravenous administration of duloxetine $(1 \mathrm{mg} / \mathrm{kg})$ significantly increased urethral baseline pressure by $15 \%$ compared with the vehicle group $(P<0.05)$. Oral administration of

TABLE 1

Inhibition of monoamine transporter binding in vitro by TAS-303 and duloxetine

The affinity of each compound was measured by the inhibition of $\left[{ }^{125}\right.$ I]RTI-55 binding for NET and DAT, and $\left[{ }^{3} \mathrm{H}\right]$ paroxetine binding for SERT to respective membranes. $K_{\mathrm{i}}$ values for receptor binding were determined from three independent experiments using seven drug concentrations. Results are shown as the mean \pm S.E.M.

\begin{tabular}{lcccccc}
\hline \multirow{2}{*}{ Compound } & \multicolumn{3}{c}{ Monoamine Transporter Binding $K_{\mathrm{i}}$} & & \multicolumn{2}{c}{ Selectivity } \\
\cline { 2 - 3 } & \multicolumn{1}{c}{ NET } & SERT & DAT & & SERT/NET & DAT/NET \\
\hline & & $n M$ & & & \\
TAS-303 & $50.9 \pm 1.9$ & $1560 \pm 77$ & $1290 \pm 69$ & & 31 & 253 \\
Duloxetine & $3.42 \pm 0.25$ & $0.283 \pm 0.033$ & $157 \pm 7$ & & 0.08 & 46 \\
\hline
\end{tabular}



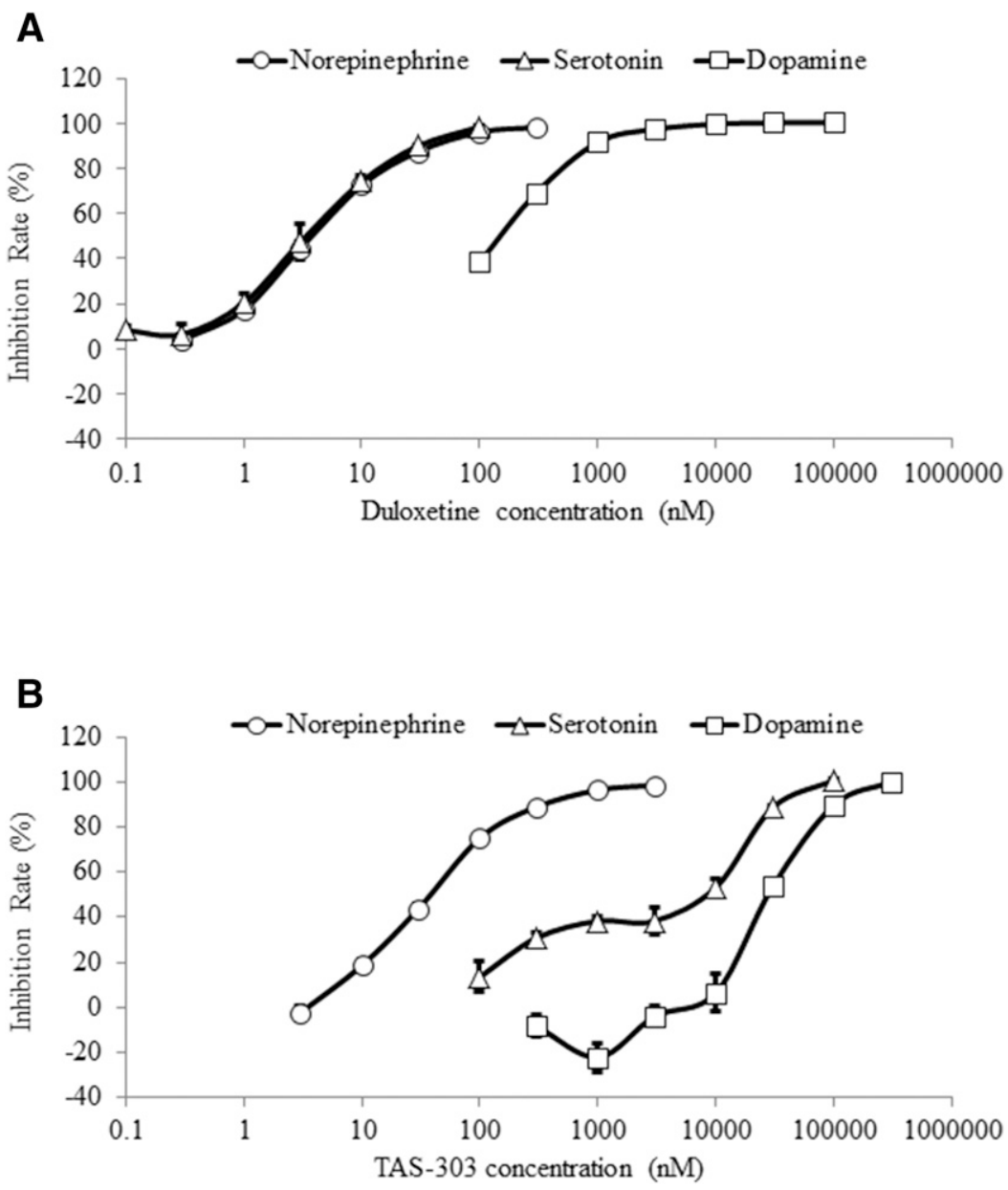

Fig. 2. Concentration-dependent inhibition of $\left[{ }^{3} \mathrm{H}\right]$ norepinephrine, $\left[{ }^{3} \mathrm{H}\right]$ serotonin, or $\left[{ }^{3} \mathrm{H}\right]$ dopamine uptake by duloxetine (A) and TAS-303 (B). Inhibition of monoamine uptake in cells expressing the norepinephrine transporter SERT or DAT by the compounds at various concentrations was evaluated. The inhibition rate was determined from three independent experiments, and data are expressed as the percentage of control-specific binding. Results are shown as the mean \pm S.E.M. $(n=3)$.
TAS-303 $(0.3,1$, and $3 \mathrm{mg} / \mathrm{kg})$ resulted in a dose-dependent increase in urethral pressure. At greater than $1 \mathrm{mg} / \mathrm{kg}$ dose of TAS-303, urethral baseline pressure significantly increased compared with the vehicle group $(P<0.05)$, and increased by $38 \%$ at a dose of $3 \mathrm{mg} / \mathrm{kg}$.

Effect of TAS-303 on LPP in VD Model Rats. SUI has been reported to mainly occur as a result of pregnancy and delivery. The VD model was selected because it is commonly used to simulate vaginal delivery, and imitates the urethral damage occurring after delivery (Lin et al., 1998; Cannon et al., 2002). A previous report (Miyazato et al., 2009) showed that intravenous injection of $1 \mathrm{mg} / \mathrm{kg}$ duloxetine significantly increased sneezeinduced LPP in VD rats. To investigate the effect of TAS-303 on urethral function in an SUI model, LPP in the rat VD model was measured after oral administration (Fig. 6). LPP was defined as the intravesical pressure at the occurrence of incontinence induced by abdominal pressure loading, and the experiment was conducted in a blinded manner. The mean LPP of VD rats was $32.5 \pm$ $1.6 \mathrm{cmH}_{2} \mathrm{O}$ and was significantly lower than that of shamoperated rats $\left(50.6 \pm 2.6 \mathrm{cmH}_{2} \mathrm{O}, P<0.01\right)$, indicating the successful establishment of the VD model. Intravenous administration of duloxetine ( $1 \mathrm{mg} / \mathrm{kg}$ ) significantly increased LPP by $20 \%$ compared with the vehicle group $(P<0.01)$. Oral administration of TAS-303 $(0.3,1$, and $3 \mathrm{mg} / \mathrm{kg})$ resulted in a dose-dependent increase in LPP. At a greater than $1 \mathrm{mg} / \mathrm{kg}$ dose of TAS-303, LPP was significantly increased compared with the vehicle group $(P<0.05)$, and increased by $26 \%$ at a dose of $3 \mathrm{mg} / \mathrm{kg}$.

Effect of TAS-303 on Blood Pressure and Heart Rate in Dogs. It has been reported that antidepressants are associated with the potential cardiovascular risks (Mago et al., 2014). Thus, the effects of TAS-303 on cardiovascular parameters in dogs were assessed to clarify whether TAS-303 would have the

TABLE 2

Inhibition of monoamine uptake in vitro by TAS-303 and duloxetine

$\mathrm{IC}_{50}$ values for monoamine uptake were determined from three independent experiments using seven drug concentrations. Results are shown as the mean \pm S.E.M.

\begin{tabular}{lcccccr}
\hline \multirow{2}{*}{ Compound } & \multicolumn{3}{c}{ Monoamine Uptake $\mathrm{IC}_{50}$} & & \multicolumn{2}{c}{ Selectivity } \\
\cline { 2 - 3 } & NET & SERT & DAT & & SERT/NET & DAT/NET \\
\hline & & $n M$ & & & \\
TAS-303 & $38.9 \pm 2.8$ & $3080 \pm 240$ & $28,300 \pm 2000$ & & 79 & 726 \\
Duloxetine & $4.03 \pm 0.28$ & $3.52 \pm 0.56$ & $149 \pm 9$ & & 0.87 & 37 \\
\hline
\end{tabular}


TABLE 3

Effect of vehicle, TAS-303, or duloxetine on NE-induced contraction of rat isolated urethral strips

$\mathrm{EC}_{50}$ of NE-induced contractions was obtained from a sigmoidal curve under variable maximum effect conditions. Results are shown as mean \pm S.E.M. ( $n=5$ for each compound in each tissue). $P>0.05$ vs. control (pretreatment).

\begin{tabular}{lccc}
\hline Compound & Concentration & $\mathrm{EC}_{50}$ & $P$ Value \\
\hline \multirow{3}{*}{ Vehicle } & $n M$ & $\log _{10} \mathrm{~mol} / l$ & \\
& & $-4.49 \pm 0.09$ & \\
& First vehicle & $-4.54 \pm 0.11$ & N.S. \\
& Second vehicle & $-4.57 \pm 0.08$ & N.S. \\
& Third vehicle & $-4.62 \pm 0.07$ & N.S. \\
& Fourth vehicle & $-4.64 \pm 0.04$ & N.S. \\
& Fifth vehicle & $-4.63 \pm 0.08$ & N.S. \\
Duloxetine & 10 & $-4.40 \pm 0.08$ & \\
& 30 & $-4.43 \pm 0.08$ & $*$ \\
& 100 & $-4.57 \pm 0.06$ & $* *$ \\
& 300 & $-4.80 \pm 0.02$ & $* *$ \\
TAS-303 & 1000 & $-5.00 \pm 0.08$ & $* *$ \\
& 10 & $-4.12 \pm 0.04$ & $* *$ \\
& 30 & $-4.48 \pm 0.12$ & N.S. \\
& 100 & $-4.69 \pm 0.08$ & $* *$ \\
& 300 & $-4.77 \pm 0.08$ & $* *$ \\
& 1000 & $-4.95 \pm 0.08$ & $* *$ \\
& & $-5.12 \pm 0.11$ & $* *$ \\
\hline
\end{tabular}

$* P<0.05 ;{ }^{* *} P<0.01$ vs. control (pretreatment) by a paired Student's $t$ test.

risk of cardiovascular side effects (Supplemental Fig. 1). The dog is selected because this is one of the most generally used animal models for assessing the effects of drugs on blood pressure and heart rate $(\mathrm{HR})$. Time course of the effects of a single oral administration of TAS-303 (1, 3, or $10 \mathrm{mg} / \mathrm{kg})$ on systolic blood pressure (SBP), diastolic blood pressure (DBP), mean blood pressure (MBP), and $\mathrm{HR}$ was evaluated in conscious dogs. Predrug values for SBP, DBP, and MBP in the vehicle-treated group were $137 \pm 4,90 \pm 8$, and $106 \pm 6 \mathrm{~mm} \mathrm{Hg}$, respectively, these values being similar to those in each TAS-303-treated group. Predrug value for $\mathrm{HR}$ in the vehicle-treated group was $79 \pm 6$ beats/min, which was similar to that in each TAS303-treated group. No significant difference between the TAS303 group (at each dose) and the vehicle group was detected in the evaluation of SBP, DBP, MBP, and HR.

Effect of TAS-303 on Immobility Time of Rats in the FST. The FST is one of the most frequently used animal models for assessing antidepressant-like effects of centrally acting antidepressants, such as selective serotonin reuptake inhibitors, SNRIs, and TCAs. It is well established that treatment with such drugs reduces the duration of immobility in the FST (Rénéric and Lucki, 1998; Guan et al., 2014). To clarify whether TAS-303 affects the CNS, the immobility time of rats in the FST was assessed. The effects of treatment with TAS-303 and the TCA imipramine on immobility time in the FST are shown in Fig. 7. Imipramine was selected as a positive control, as the effect of this agent on immobility time in the FST is well described (Guan et al., 2014). The immobility time in the imipramine group was significantly lower than that in the vehicle group $(P<0.01)$. In contrast, no significant difference between the TAS-303 group (at each dose) and the vehicle group was detected.

\section{Discussion}

In this article, we report on the pharmacological properties of the novel NRI inhibitor TAS-303. The pharmacological profile of TAS-303 (potency, selectivity, and in vivo efficacy) and its pharmacokinetic profile were evaluated. To further support the rationale for norepinephrine reuptake inhibition, we also examined the effect of TAS-303 on plasma norepinephrine levels in rats. Moreover, we estimated the antidepressant-like effect of TAS-303 using the FST. These studies characterize TAS-303 as an orally available, potent, and selective NRI with a lesser risk of CNS adverse events.

We investigated the direct effect of TAS-303 on monoaminergic and cholinergic receptors. The percentage of the agonistic activity of TAS-303 $(10 \mu \mathrm{M})$ on the adrenergic $\alpha_{1 \mathrm{~A}}$ receptor, $\alpha_{1 \mathrm{~B}}$ receptor, or $5-\mathrm{HT}_{2 \mathrm{c}}$ receptor was $-4 \%, 4 \%$, or $0 \%$, respectively. The ligand-binding inhibition of TAS-303 $(10 \mu \mathrm{M})$ on the adrenergic $\alpha_{1 \mathrm{D}}$ receptor, nicotinic acetylcholine receptor, or $5-\mathrm{HT}_{1 \mathrm{~A}}$ receptor was $7 \%, 12 \%$, $7 \%$, respectively (data not shown). Therefore, TAS-303 is considered to have almost no direct effect on the receptors associated with urethral smooth muscle and EUS contraction. Among the three monoamine transporters (NET, SERT, and DAT), TAS-303 selectively inhibited NET [inhibition constant $\left(K_{\mathrm{i}}\right)$, $50.9 \mathrm{nM}]$ and also inhibited the uptake of $\left[{ }^{3} \mathrm{H}\right]$ norepinephrine $\left(\mathrm{IC}_{50}, 38.9 \mathrm{nM}\right)$. Furthermore, the concentration-response curve for NE-induced urethral contractions was shifted to the left after treatment with TAS-303 in the urethral muscle strip experiment. The effect of TAS-303 on plasma monoamine levels was evaluated, and the elevation of norepinephrine level, but not the other monoamines tested, in the plasma was observed after administration of $3 \mathrm{mg} / \mathrm{kg}$ TAS-303. In the rat efficacy study, treatment with $3 \mathrm{mg} / \mathrm{kg}$ TAS-303 produced an increase in urethral pressure, where the $C_{\max }$ of TAS-303 was above the $\mathrm{IC}_{50}$ of the in vitro uptake assay $(38.9 \mathrm{nM})$. We have confirmed that TAS-303 is a substrate for P-glycoprotein, indicating that this agent would have a low ability to penetrate the blood-brain barrier (data not shown). Moreover, we have confirmed that total ${ }^{14} \mathrm{C}$ radioactivity in the plasma for orally administered ${ }^{14} \mathrm{C}$-labeled TAS-303 $(3 \mathrm{mg} / \mathrm{kg})$ peaked at 1 hour after administration using quantitative whole-body autoradiography, and no ${ }^{14} \mathrm{C}$ radioactivity was observed in the cerebrum, cerebellum, or spinal cord (data not shown). Therefore, TAS-303 is not likely to enter the CNS. These findings suggest that the peripheral elevation of NE levels induced by TAS-303 administration underlies the increase in urethral pressure in rats.

Previous animal studies have suggested that NE and serotonin are involved in the neural control of lower urinary tract function (Gajewski et al., 1984; Downie and Bialik, 1988; Thor et al., 1990; Danuser and Thor, 1996; Espey et al., 1998; Conlon et al., 2009). Miyazato et al. (2008) reported that duloxetine acted in both the CNS and the PNS and stated that duloxetine seems to be superior to the NRI nisoxetine in enhancing active urethral closure, possibly because of the additional activation of the serotonergic system by duloxetine. In contrast to duloxetine, it is suggested that TAS-303 peripherally inhibited NET without affecting NET in the CNS. Concern remains about the efficacy of TAS-303 for patients with SUI, because this agent has inhibitory activity against peripheral NET alone. To estimate the efficacy of TAS-303, we compared its effect to that of duloxetine on urethral resistance in vivo. In this study, TAS-303 significantly increased urethral pressure by $38 \%$ in normal rats. In the same assessment, the clinically approved agent duloxetine produced a $15 \%$ increase in urethral pressure. Furthermore, 

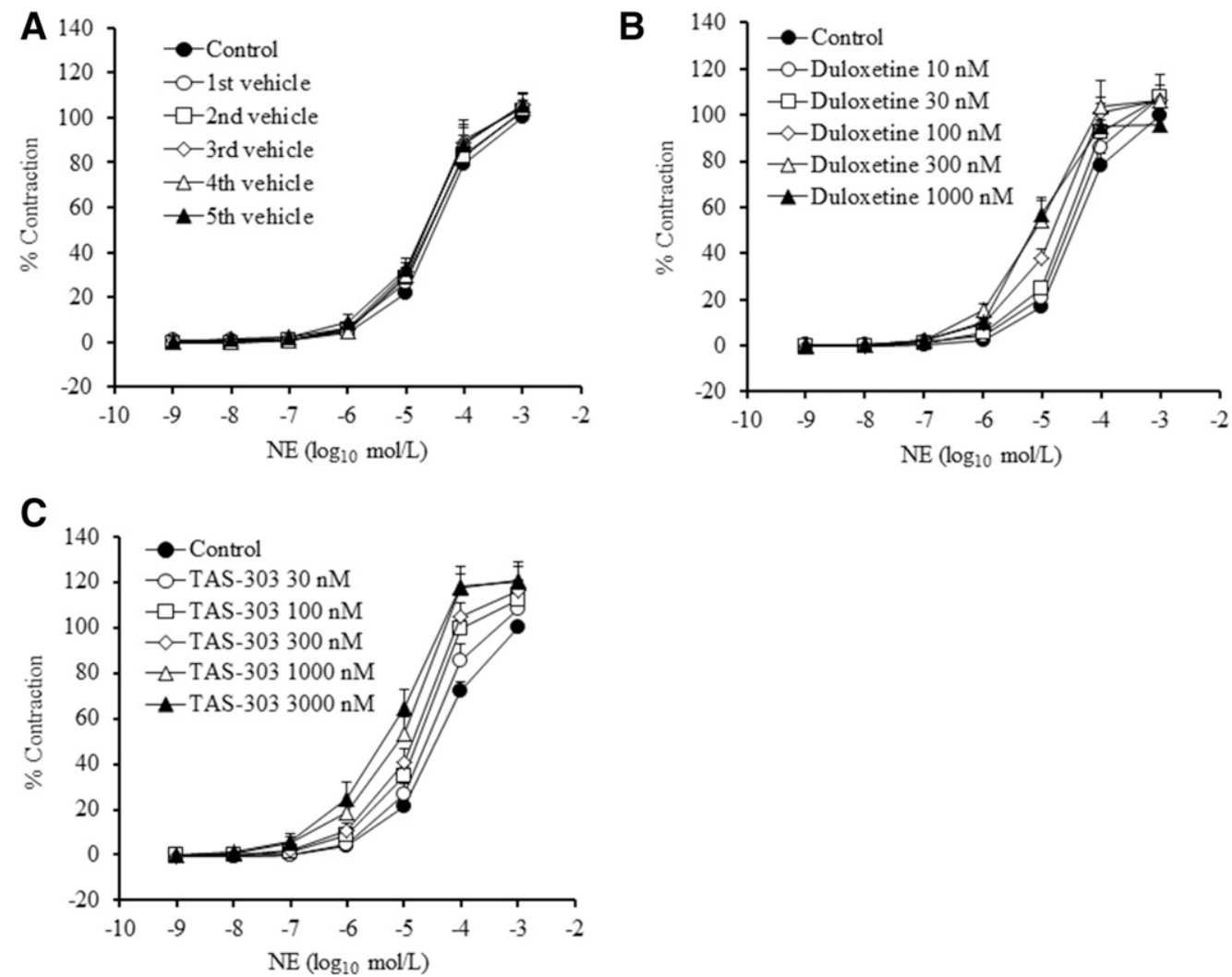

Fig. 3. Concentration-response curves for NE in rat isolated urethral muscle in the presence of vehicle (A), TAS-303 (B), and duloxetine (C). The NE $(1 \mathrm{mM})$-induced maximum contraction determined in the vehicle alone (prior to evaluation of compounds) was designated as $100 \%$ contraction, and the urethral contractions for each compound were expressed as relative values (\%). Results are shown as the mean \pm S.E.M. $(n=5$ for each compound in each tissue).

TAS-303 significantly increased LPP by $26 \%$ in VD rats. In the same assessment, intravenous administration of duloxetine produced a $20 \%$ increase of LPP in VD rats. Therefore, TAS303 increased the urethral pressure of normal rats and increased the LPP of VD rats to levels comparable to those with duloxetine. These results suggest that the inhibition of peripheral NET may be sufficient to increase urethral resistance. This suggestion is supported by a previous report (Klarskov et al., 2009), in which the selective NRI esreboxetine exhibited clinical efficacy in a US study of patients with SUI. In addition, (Fujimori et al., 2015) evaluated the in vivo potency of the peripheral-selective NRI compound 12 on normal rat LPP compared with esreboxetine. Compound 12 produced an elevation in LPP, and the maximum response was comparable to that for esreboxetine. Considering the negative CNS-penetrating property of compound 12 , the increasing effect on urethral pressure in rats was suggested to be mediated mainly by the inhibition of peripheral NET. In this study, we selected $1 \mathrm{mg} / \mathrm{kg}$ as the dose of duloxetine, because this dose is often used to produce maximal effects on urethral pressure (Kamo and Hashimoto, 2007; Miyazato et al., 2015). It has been reported that the $C_{\max }$ of duloxetine after intravenous administration of radiolabeled duloxetine (5 mg/kg) to rats was $14 \mu \mathrm{M}$ (Application Brochure; Eli Lilly Japan K.K., Kobe, Japan), and this concentration is sufficiently higher than the $C_{\max }(116 \mathrm{nM})$ after oral administration of the clinical dose $(40 \mathrm{mg})$ in humans (Interview Form for Cymbalta, revised in 2017, Eli Lilly Japan K.K.). Thus, the plasma level of duloxetine after intravenous administration of
$1 \mathrm{mg} / \mathrm{kg}$ would reach a value equivalent to or greater than the clinical dose. These findings indicate that TAS-303 has therapeutic potential as an SUI treatment. However, a limitation of this study is the difference in the administration route between TAS-303 and duloxetine, which did not allow adequate assessment of the effect of both drugs in the in vivo study. Accordingly, the efficacy of TAS-303 in patients with SUI needs to be elucidated in clinical trials.

$\mathrm{NE}$ is well known to bind to adrenergic receptors in the blood vessels and myocardium, which caused increase in blood pressure and heart rate. Thus, NRIs are considered to have potential cardiovascular risks. However, previous reports (Tanum 2000; Versiani et al., 2000) have shown that in patients with depression receiving a selective NRI, reboxetine, there was a tendency toward orthostatic changes in blood pressure, but this was not clinically significant. Moreover, a review of the literature about the cardiovascular safety profile

\section{TABLE 4}

Pharmacokinetic parameters after single oral administration of TAS-303 at 1,3 , or $10 \mathrm{mg} / \mathrm{kg}$ in normal female rats

Results are shown as the mean \pm S.E.M.

\begin{tabular}{ccc}
\hline Dose & $\mathrm{T}_{\max }$ & $C_{\max }$ \\
\hline & $h$ & $n M$ \\
$1 \mathrm{mg} / \mathrm{kg}$ & $0.75 \pm 0.29$ & $11.7 \pm 5.0$ \\
$3 \mathrm{mg} / \mathrm{kg}$ & $0.75 \pm 0.29$ & $49.1 \pm 13.9$ \\
$10 \mathrm{mg} / \mathrm{kg}$ & $1.25 \pm 0.50$ & $453.0 \pm 28.8$
\end{tabular}

$\mathrm{T}_{\max }$, time to peak concentration. 


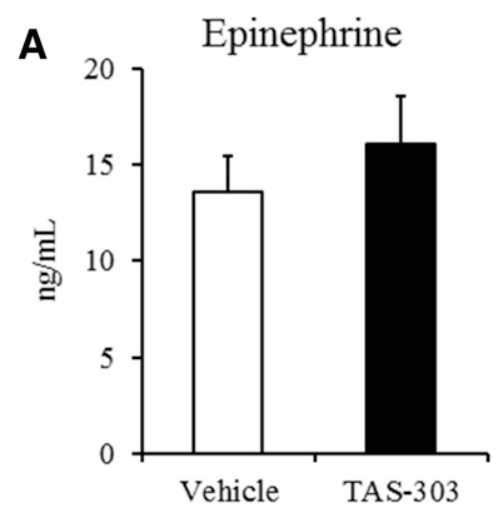

C

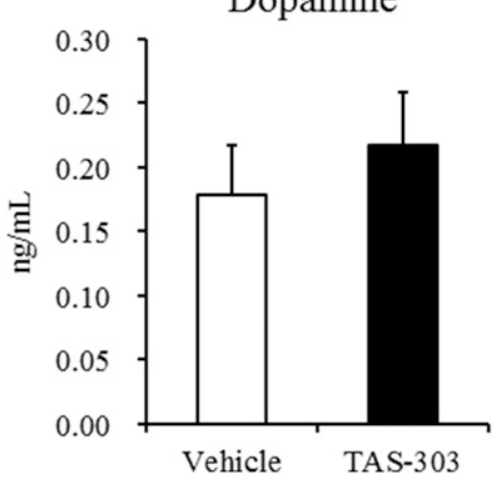

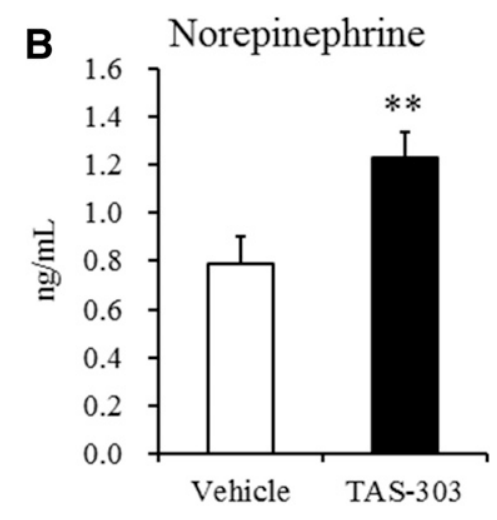

D

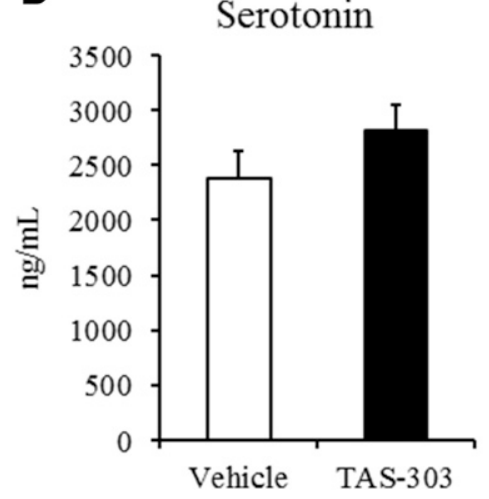

Fig. 4. Effect of TAS-303 (3 mg/kg) administration for 7 days on plasma concentrations of epinephrine (A), norepinephrine (B), dopamine (C), and serotonin (D) in rats. Results are shown as the mean \pm S.E.M. $(n=9$ to 10). $* * P<0.01$ vs. vehicle by an unpaired Student's $t$ test. of duloxetine has demonstrated that the use of duloxetine does not appear to be associated with significant cardiovascular risks in patients with depression or diabetic neuropathic pain (Wernicke et al., 2007). Therefore, it is considered that NET inhibition would have little risk of clinically significant cardiovascular side effects. In this report, a single dose of TAS-303 $(10 \mathrm{mg} / \mathrm{kg})$ to dogs resulted in no significant change in blood pressure and heart rate, where the $C_{\max }(431 \mathrm{nM}$; data not shown) of TAS-303 was above the $C_{\max }(49 \mathrm{nM})$ in the measurement of rat urethral pressure. These findings suggested that NRIs have the selectivity for urethral efficacy over cardiovascular events. There is a need for future studies to elucidate the selectivity. It remains to be confirmed in clinical trials of TAS-303 whether increases in urethral pressure can be achieved in the absence of cardiovascular events with NET inhibition.

Antidepressants are required to be labeled with a black box warning about the increased risk of suicide (Friedman and Leon, 2007). It has been reported that the serotonin system is associated with the onset of the side effect mentioned above (Oelke et al., 2006; Mann, 2013). Consequently, duloxetine is not approved for the treatment of SUI in the United States. To assess the risk of suicide associated with TAS-303, the FST was conducted in rats. It is well established that treatment with centrally acting antidepressants, including SNRIs and TCAs, reduce the immobility time in the FST (Guan et al.,

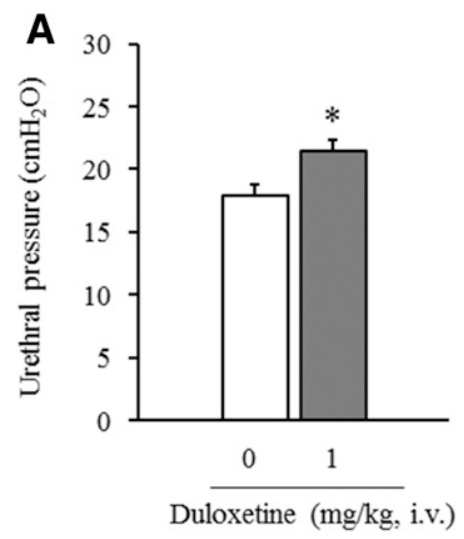

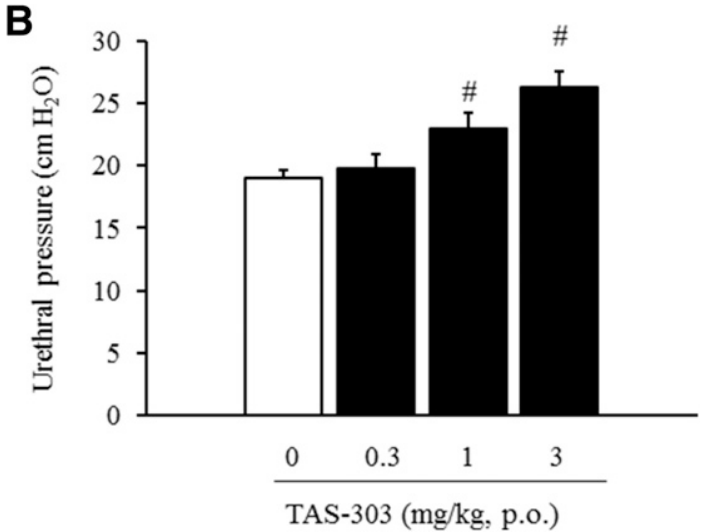

Fig. 5. Effects of duloxetine and TAS-303 on urethral baseline pressure in rats. (A) Vehicle or duloxetine $(1 \mathrm{mg} / \mathrm{kg})$ was administered intravenously, and the urethral baseline pressure was measured for 30 minutes after administration. (B) Vehicle or TAS-303 $(0.3,1$, or $3 \mathrm{mg} / \mathrm{kg})$ was administered orally, and the urethral baseline pressure was measured for a period of 30 minutes beginning 1 hour after administration. Results are shown as the mean \pm S.E.M. of five rats in each group. ${ }^{*} P<0.05$ vs. vehicle (physiologic saline) by a paired Student's $t$ test. $\# P<$ 0.05 vs. vehicle by Williams' test. 


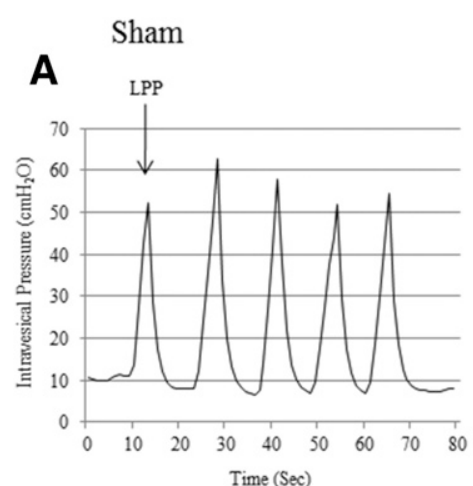

D

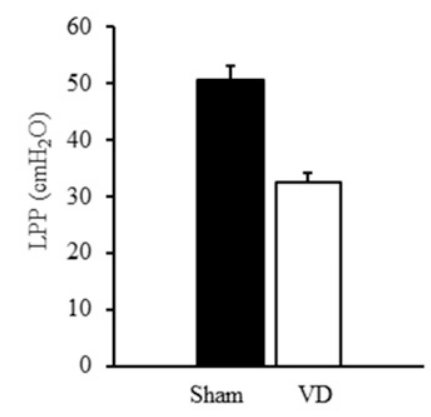

B

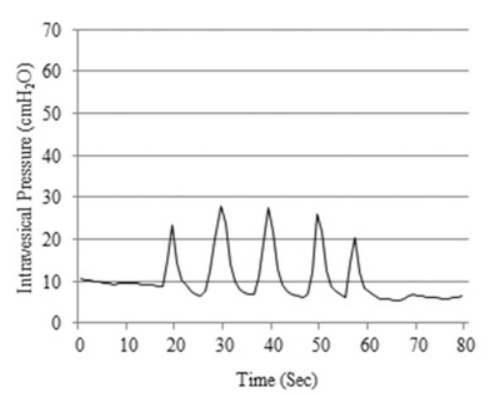

E

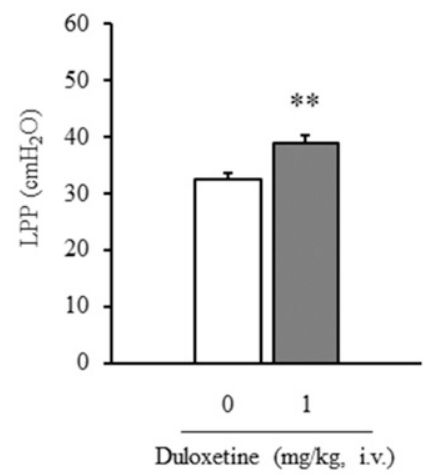

C

VD (TAS-303 $3 \mathrm{mg} / \mathrm{kg}$ )

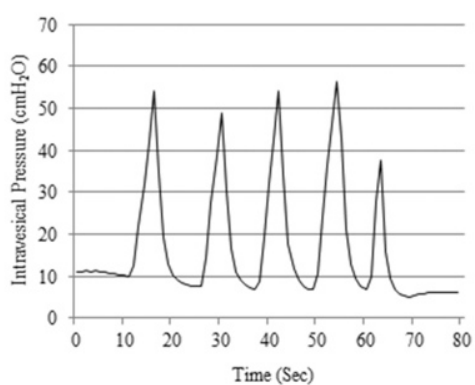

$\mathbf{F}$

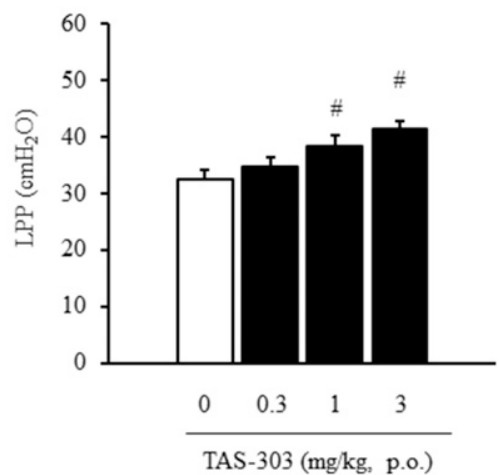

Fig. 6. Effects of duloxetine and TAS-303 on LPP in VD rats. Representative traces of intravesical changes at 1 hour after the administration of sham (A), vehicle (B), or TAS-303 (C) (3 mg/kg) are shown. LPP is the intravesical pressure at the time of the occurrence of urine leakage (arrow). (D) Quantification of LPP in sham or VD rats. (E) Vehicle or duloxetine $(1 \mathrm{mg} / \mathrm{kg}$ ) was administered intravenously, and LPP was measured at 5 minutes after administration. (F) Vehicle or TAS-303 $(0.3,1$, or $3 \mathrm{mg} / \mathrm{kg}$ ) was administered orally, and LPP was measured at 1 hour after administration. Results are shown as the mean \pm S.E.M. of 10 rats in each group. ${ }^{* * P}<0.01$ vs. vehicle (physiologic saline) by a paired Student's $t$ test. $\# P<0.05$ vs. vehicle by Williams' test.

2014). As described previously, the TCA imipramine $(60 \mathrm{mg} / \mathrm{kg})$ reduced the immobility time of rats in the FST. A previous study (Rénéric and Lucki, 1998) showed that subcutaneous administration of duloxetine at greater than $10 \mathrm{mg} / \mathrm{kg}$ significantly decreased the immobility time of rats in the FST. These findings suggest that duloxetine exhibits an antidepressant-like effect in the FST. Clinically, duloxetine is often prescribed for both major depressive disorder and SUI at a dose of $40 \mathrm{mg} / \mathrm{d}$. Therefore, it is assumed that the anti-SUI effect and antidepressant effect are produced in the same dose range. In contrast to imipramine, TAS-303 had no effect on the immobility time of rats in the FST, even at a high dose (100 mg/kg). These findings suggest that TAS-303 presents little risk of central adverse effects at an effective dose for urethral function.

TAS-303 demonstrated selective NET inhibitory activity and produced a significant increase in urethral resistance in rats, with a maximum effect comparable to that of the clinically effective drug duloxetine, suggesting that this agent has a therapeutic potential for patients with SUI. Moreover, TAS-303 showed no effect on the immobility time of rats in the FST test, indicating that this agent would have a lesser risk of central adverse effects. Recently, a double-blind, single-dose, placebo-controlled crossover study of TAS-303 at a dose of $18 \mathrm{mg}$ was conducted in 16 patients with SUI (Yono et al., 2017). There were no reports of serious adverse events, significant changes in blood pressure, or abnormal urinalysis results, suggesting that this agent was well tolerated. At present, a phase II randomized clinical study of TAS-303 in female patients with SUI is being conducted (NCT02906683).

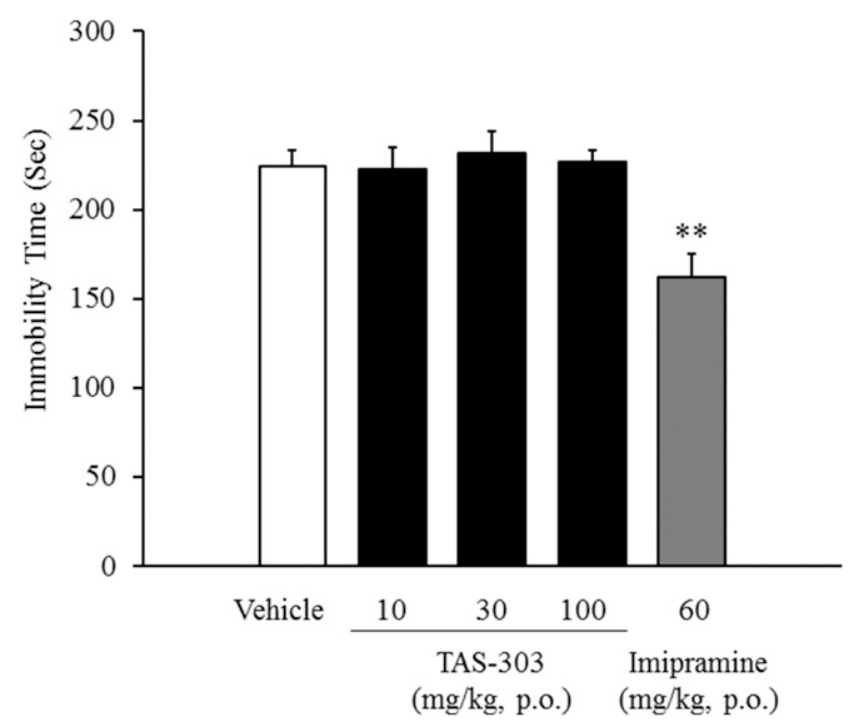

Fig. 7. Effects of TAS-303 and imipramine on the immobility time of rats in the FST. The measurement of immobility time was conducted at 1 hour after the oral administration of vehicle, TAS-303 $(10,30,100 \mathrm{mg} / \mathrm{kg})$, or imipramine $(60 \mathrm{mg} / \mathrm{kg})$. Results are shown as the mean \pm S.E.M. of 10 rats in each group. ${ }^{* * P}<0.01$ vs. vehicle by an unpaired Student's $t$ test. 


\section{Authorship Contributions}

Participated in research design: Mizutani, Sakakibara, Komuro, and Sasaki.

Conducted experiments: Mizutani, Sakakibara, and Komuro.

Performed data analysis: Mizutani, Sakakibara, and Komuro.

Wrote or contributed to the writing of the manuscript: Mizutani and Sakakibara.

\section{References}

Abrams P, Cardozo L, Fall M, Griffiths D, Rosier P, Ulmsten U, van Kerrebroeck P, Victor A, and Wein A; Standardisation Sub-committee of the International Continence Society (2002) The standardisation of terminology of lower urinary tract function: report from the standardisation sub-committee of the International Continence Society. Neurourol Urodyn 21:167-178.

Cannon TW, Wojcik EM, Ferguson CL, Saraga S, Thomas C, and Damaser MS (2002) Effects of vaginal distension on urethral anatomy and function. BJU Int $\mathbf{9 0}$ 403-407.

Conlon K, Christy C, Westbrook S, Whitlock G, Roberts L, Stobie A, and McMurray G (2009) Pharmacological properties of 2-((R-5-chloro-4-methoxymethylindan-1-yl)$1 \mathrm{H}$-imidazole (PF-3774076), a novel and selective alpha1A-adrenergic partial agonist, in in vitro and in vivo models of urethral function. J Pharmacol Exp Ther 330:892-901.

Coyne KS, Kvasz M, Ireland AM, Milsom I, Kopp ZS, and Chapple CR (2012) Urinary incontinence and its relationship to mental health and health-related quality of life in men and women in Sweden, the United Kingdom, and the United States. Eur Urol 61:88-95.

Danuser H and Thor KB (1996) Spinal 5- $\mathrm{HT}_{2}$ receptor-mediated facilitation of pudendal nerve reflexes in the anaesthetized cat. Br J Pharmacol 118:150-154.

Dmochowski RR, Miklos JR, Norton PA, Zinner NR, Yalcin I, and Bump RC; Duloxetine Urinary Incontinence Study Group (2003) Duloxetine versus placebo for the treatment of North American women with stress urinary incontinence. $J$ Urol 170:1259-1263.

Downie JW and Bialik GJ (1988) Evidence for a spinal site of action of clonidine on somatic and viscerosomatic reflex activity evoked on the pudendal nerve in cats. J Pharmacol Exp Ther 246:352-358.

Espey MJ, Du HJ, and Downie JW (1998) Serotonergic modulation of spinal ascending activity and sacral reflex activity evoked by pelvic nerve stimulation in cats. Brain Res 798:101-108.

Friedman RA and Leon AC (2007) Expanding the black box-depression, antidepressants, and the risk of suicide. N Engl J Med 356:2343-2346.

Fujimori I, Yukawa T, Kamei T, Nakada Y, Sakauchi N, Yamada M, Ohba Y, Takiguchi M, Kuno M, Kamo I, et al. (2015) Design, synthesis and biological evaluation of a novel series of peripheral-selective noradrenaline reuptake inhibitor. Bioorg Med Chem 23:5000-5014.

Gajewski J, Downie JW, and Awad SA (1984) Experimental evidence for a central nervous system site of action in the effect of alpha-adrenergic blockers on the external urinary sphincter. J Urol 132:403-409.

Gerten KA, Markland AD, Lloyd LK, and Richter HE (2008) Prolapse and incontinence surgery in older women. J Urol 179:2111-2118.

Grimby A, Milsom I, Molander U, Wiklund I, and Ekelund P (1993) The influence of urinary incontinence on the quality of life of elderly women. Age Ageing 22:82-89.

Guan XT, Shao F, Xie X, Chen L, and Wang W (2014) Effects of aspirin on immobile behavior and endocrine and immune changes in the forced swimming test: comparison to fluoxetine and imipramine. Pharmacol Biochem Behav 124:361-366.

Hannestad YS, Rortveit G, Sandvik H, and Hunskaar S; Norwegian EPINCONT study. Epidemiology of Incontinence in the County of Nord-Trøndelag (2000) A community-based epidemiological survey of female urinary incontinence: the Norwegian EPINCONT study. Epidemiology of Incontinence in the County of Nord-Trøndelag. J Clin Epidemiol 53:1150-1157.

Kamo I and Hashimoto T (2007) Involvement of reflex urethral closure mechanisms in urethral resistance under momentary stress condition induced by electrical stimulation of rat abdomen. Am J Physiol Renal Physiol 293:F920-F926.

Klarskov N, Scholfield D, Soma K, Darekar A, Mills I, and Lose G (2009) Measurement of urethral closure function in women with stress urinary incontinence. J Urol 181:2628-2633, discussion 2633

Lagro-Janssen T and van Weel C (1998) Long-term effect of treatment of female incontinence in general practice. Br J Gen Pract 48:1735-1738.
Lin AS, Carrier S, Morgan DM, and Lue TF (1998) Effect of simulated birth trauma on the urinary continence mechanism in the rat. Urology 52:143-151.

Mago R, Tripathi N, and Andrade C (2014) Cardiovascular adverse effects of newer antidepressants. Expert Rev Neurother 14:539-551.

Maman K, Aballea S, Nazir J, Desroziers K, Neine ME, Siddiqui E, Odeyemi I, and Hakimi Z (2014) Comparative efficacy and safety of medical treatments for the management of overactive bladder: a systematic literature review and mixed treatment comparison. Eur Urol 65:755-765.

Mann JJ (2013) The serotonergic system in mood disorders and suicidal behaviour. Philos Trans R Soc Lond B Biol Sci 368:20120537.

Minassian VA, Stewart WF, and Wood GC (2008) Urinary incontinence in women: variation in prevalence estimates and risk factors. Obstet Gynecol 111:324-331.

Miyazato M, Kaiho Y, Kamo I, Chancellor MB, Sugaya K, de Groat WC, and Yoshimura N (2008) Effect of duloxetine, a norepinephrine and serotonin reuptake inhibitor, on sneeze-induced urethral continence reflex in rats. Am J Physiol Renal Physiol 295:F264-F271.

Miyazato M, Kitta T, Kaiho Y, Oshiro T, Saito S, Chancellor MB, de Groat WC, and Yoshimura N (2015) Effects of duloxetine on urethral continence reflex and bladder activity in rats with cerebral infarction. J Urol 194:842-847.

Miyazato M, Yoshimura N, Nishijima S, and Sugaya K (2009) Roles of glycinergic and gamma-aminobutyric-ergic mechanisms in the micturition reflex in rats. Low Urin Tract Symptoms 1(S1 Suppl 1):S70-S73.

Mørkved S and Bø K (2000) Effect of postpartum pelvic floor muscle training in prevention and treatment of urinary incontinence: a one-year follow up. BJOG 107: 1022-1028.

Norton PA, Zinner NR, Yalcin I, and Bump RC; Duloxetine Urinary Incontinence Study Group (2002) Duloxetine versus placebo in the treatment of stress urinary incontinence. Am J Obstet Gynecol 187:40-48.

Oelke M, Roovers JP, and Michel MC (2006) Safety and tolerability of duloxetine in women with stress urinary incontinence. BJOG 113 (Suppl 1):22-26.

Pérez-Martínez FC, Vela-Navarrete R, Virseda J, Ocaña AV, Lluel P, Rekik M, Bienaymé H, Ferté J, Attali P, and Palea S (2011) Halothane-anesthetized rabbit: a new experimental model to test the effects of besipirdine and duloxetine on lower urinary tract function. Urol Int 86:210-219.

Porsolt RD, Anton G, Blavet N, and Jalfre M (1978) Behavioural despair in rats: a new model sensitive to antidepressant treatments. Eur J Pharmacol 47:379-391.

Rénéric JP and Lucki I (1998) Antidepressant behavioral effects by dual inhibition of monoamine reuptake in the rat forced swimming test. Psychopharmacology (Berl) 136:190-197.

Sarkar PK and Ritch AE (2000) Management of urinary incontinence. J Clin Pharm Ther 25:251-263.

Swithinbank LV and Abrams P (1999) The impact of urinary incontinence on the quality of life of women. World J Urol 17:225-229.

Tanum L (2000) Reboxetine: tolerability and safety profile in patients with major depression. Acta Psychiatr Scand Suppl 402:37-40.

Thor KB (2003) Serotonin and norepinephrine involvement in efferent pathways to the urethral rhabdosphincter: implications for treating stress urinary incontinence. Urology 62(4 Suppl 1):3-9.

Thor KB, Hisamitsu T, and de Groat WC (1990) Unmasking of a neonatal somatovesical reflex in adult cats by the serotonin autoreceptor agonist 5-methoxy-N,Ndimethyltryptamine. Brain Res Dev Brain Res 54:35-42.

Versiani M, Amin M, and Chouinard G (2000) Double-blind, placebo-controlled study with reboxetine in inpatients with severe major depressive disorder. J Clin Psychopharmacol 20:28-34.

Wernicke J, Lledó A, Raskin J, Kajdasz DK, and Wang F (2007) An evaluation of the cardiovascular safety profile of duloxetine: findings from 42 placebo-controlled studies. Drug Saf 30:437-455.

Woo LL, Hijaz A, Pan HQ, Kuang M, Rackley RR, and Damaser MS (2009) Simulated childbirth injuries in an inbred rat strain. Neurourol Urodyn 28:356-361.

Yono M, Kimura M, Inoue Y, Furukawa K, Ito K, Tsuruya K, Nagaoka M, Hoashi K, and Irie S (2017) A double-blind, placebo-controlled clinical pharmacological study of TAS-303 in female patients with stress urinary incontinence, in Proceedings of ICS 2017; 2017 September 12-15; Florence, Italy. pp A382, The International Continence Society, Bristol, UK.

Address correspondence to: Hiroya Mizutani, Discovery and Preclinical Research Division, Taiho Pharmaceutical Co., Ltd., 3 Okubo, Tsukuba, Ibaraki 300-2611, Japan. E-mail: hiro-mizutani@taiho.co.jp 